\title{
The histological and histochemical changes in the kidney of rabbit induced by diazinon
}

\author{
S.A. Sadiq and M.T. Jarjees \\ Department of Anatomy, College of Medicine, University of Mosul, Mosul, Iraq \\ Email: Saddam Alrawi@gmail.com, mtt19602003@yahoo.com
}

(Received February 28, 2018; Accepted April 22, 2018)

\begin{abstract}
Diazinon (DZN) is a commonly used Organophosphorus (OP) pesticide to control a variety of insects in agriculture and in the environment. The aim of this project is to study the effects of organophospherous pesticide (Diazinon) on histological and histochemical of kidney in male rabbit. The present study is based upon observations made on 24 male Baladi rabbits, which was divided into: 3 groups: Eight animals each, the whole body of the rabbit was dipped in 10 liters of the diazinon solution, while sparing the head for 10 seconds. Group one (control group) was dipped in water only. Animals of Group 2; were dipped in diazinon solution dipped every 2 days for 4 weeks, and Group 3 were dipped in diazinon solution every 7days for two months. Decreased in body weight was noticed in group 2 and group 3 may be due to increases in the exposed doses and increased accumulation of DZN in the blood of the exposure animals. Histological changes in group 2 and 3 are similar, renal tubules were severely damaged with cytoplasmic vacuolation and atrophy of some glomeruli. Blood capillaries in between the degenerated tubules were congested; the urine spaces are widening, and fibrosis inters tubules in group 3 only. Exposure of animals to diazinon caused extensive changes in histopathologicaly as well as histochemicaly in the kidney of group 2 and group 3. But very marked changes in group 3.
\end{abstract}

Keywords: Diazinon, kidney

Available online at http://www.vetmedmosul.com

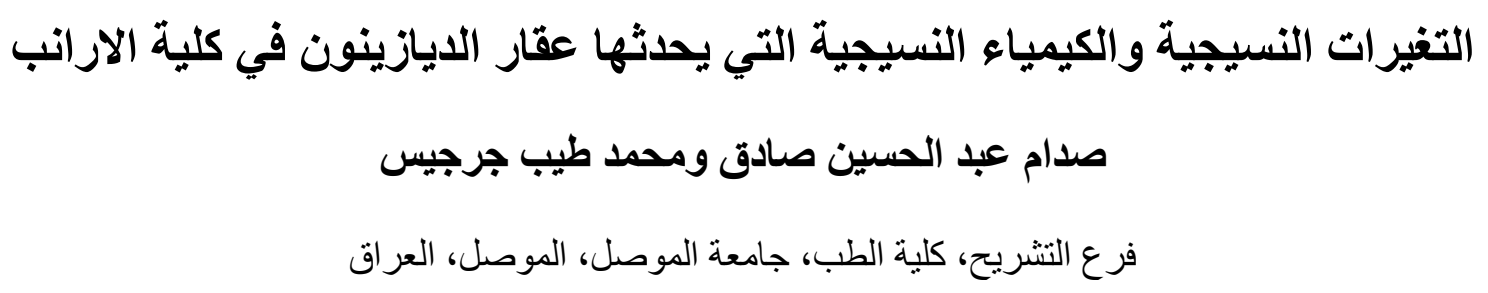

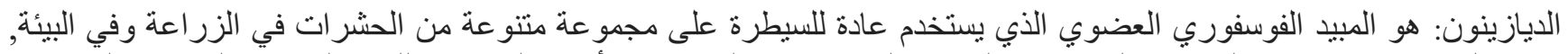

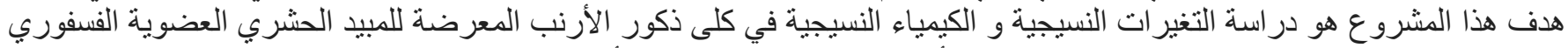

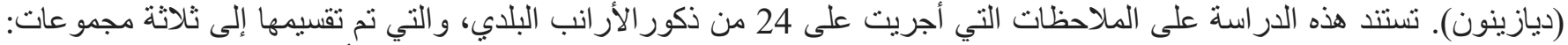

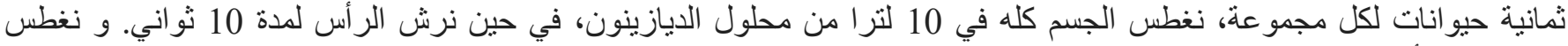

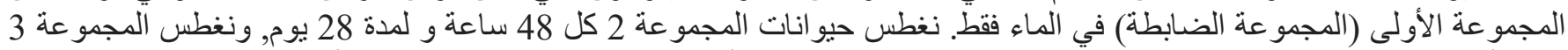

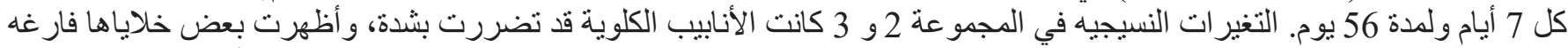

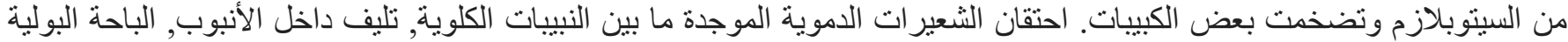

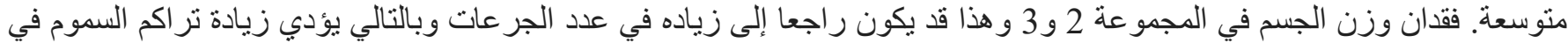

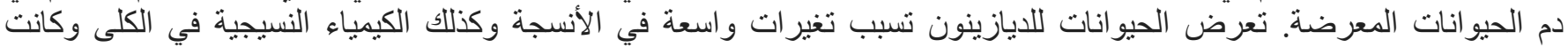

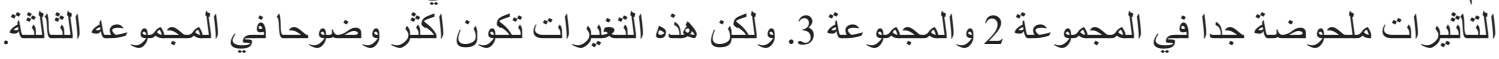




\section{Introduction}

Organophospherous compounds (OP) are part of large group of pesticides that have been developed in the last 50 years. Diazinon is the common name of an organophospherous insecticide used to control pest insects (1). Diazinon poisonings effects on mammalian cells were studied by researchers (2), Diazinon toxicity induce oxidative stress resulting in hematological changes, neurotoxicity, hepatotoxicity, nephrotoxicity, cardiac toxicity and both male and female reproductive toxicity (3).

Diazinon inhibits the enzyme acetyl cholinesterase (AChE), which hydrolyzes the neurotransmitter acetylcholine (ACh) in cholinergic synapses and neuromuscular junctions. This results in abnormal accumulation of ACh in the nervous system (4).

Diazinon exposure, whether from ingestion, skin contact, or inhalation can result in nervous system health effects, these effects may include watery eyes, running nose, and loss of appetite, coughing, urination, diarrhea, stomach pain, and vomiting. Typically, these symptoms are followed by head and body tremors, muscle tetany, stiffness, weakness with paresis and paralysis. Tachycardia and mydriasis are also possible with massive oral exposures. Central nervous system signs and symptoms may also be present such as restlessness and/or hyperactivity, depressed respiration, anxiety, depression, clonic-tonic seizures, and coma (5).

The effect of diazinon on body weight was controversial, some studies showed significant decreased in body weight. (6-8) Significant weight loss was appeared after 20 days of dermal contacts with the toxicant (9), with toxic effect of different doses of diazinon on body weight (10).

Histopathological examination showed lesions in kidney tissues produced by Diazinon, and we observed shrinkage of glomerulus, tubular dilation, glomerular hyper cellularity, hypertrophy of tubular epithelium, degeneration of renal tubules, interstitial edema, necrotic cells in the glomerulus and renal tubules (11-12).

\section{Materials and methods}

\section{Experimental rabbits}

Twenty-four male local rabbits weighing $1.2-1.4 \mathrm{Kg}$ were housed in the Experimental research unit, College of Medicine, University of Mosul, Mosul, Iraq and used in the present study, at controlled light and temperature and provided with chow and fresh tap water. The whole body of the rabbit was dipped in 10 liters of the diazinon solution, with sparing the head for 10 second. While the control group were dipped in water only. used diazinon-60 EC, made in Jordon (VAPCO), was used as a dip or spray after dilution with water. $1 \mathrm{ml} / 1$ liter, the LD50 of diazinon in males is $250 \mathrm{mg} / \mathrm{kg}$ body weight.

\section{Experimental design}

The experimental rabbits were randomly divided into three symmetric groups, eight animals for each. Group 1: The first group was dipped into tap water and served as a control group. Group 2: Animals were dipped in diazinon solution every 48 hrs. For 28 days. Group 3: Animals were dipped in diazinon solution every 7 days, for 56 days.

\section{Histological procedures}

Specimens of kidney were dissected and washed with normal saline, and then cut into slices with an average thickness of 4-5mm,the slices were fixed for more than 24 hours in $10 \%$ neutral buffered formalin (13), dehydration of the slices were made in ascending through ethanol alcohol series, using $70 \%$ ethanol for 1 hour, followed by two changes of $90 \%$ ethanol with a period of 1 hour each, and then two changes of absolute ethanol with the second one left over night, after dehydration the slices cleared twice with xylene for 1 hour each, and then embedded in three changes of paraffin with a melting point of 56-58c, 1 hour each, the section mounted on the glass slides, and kept for 30 minutes in the vacuum-drying oven at 60 deparaffinization in two changes of xylene for 5 minutes each was carried out, then the section transferred to graded ethanol, absolute, $70 \%$ and $95 \%$ ethanol, two minutes each, and finally, the sections were hydrated in the distilled water for 2 minutes to be ready for staining.

\section{Results}

\section{Physical Observations}

The animals of the control group stayed alive till the end of the experiment. They were active, responded very quickly to stimuli, and they had good appetite, whereas the animals of the group 2 and 3 suffered from a decrease in activity, and their response to stimuli and food intake was less than normal. Itching, diarrhea.

\section{Histological Findings (Group 2 and group 3)}

In comparison to control group (Fig. 1), the sections of kidney showed glomeruli were atrophied, and their cells showed cytoplasmic vacuolation, there is inter renal tubules fibrosis in group 2 only, the urine spaces are widened, diffuse prominent congested blood vessels in some glomerulus, infiltrations of lymphocyte in glomerulus (Fig. 2 and 3).

\section{Histochemical findings}

A strong positive reaction to Periodic acid Schiff's (PAS) and Bests carmine (B.C) was seen in the cytoplasm of proximal convoluted tubular epithelium, the tubular 
luminal brush border, basement membrane of tubules, basement membrane of glomerular capsule and the glomeruli, (Fig. 4 - 9).

\section{Body's weight results}

Clinical signs indicated that diazinon induced toxicity was shown by a marked decrease in body weight in group 2 and group 3 .

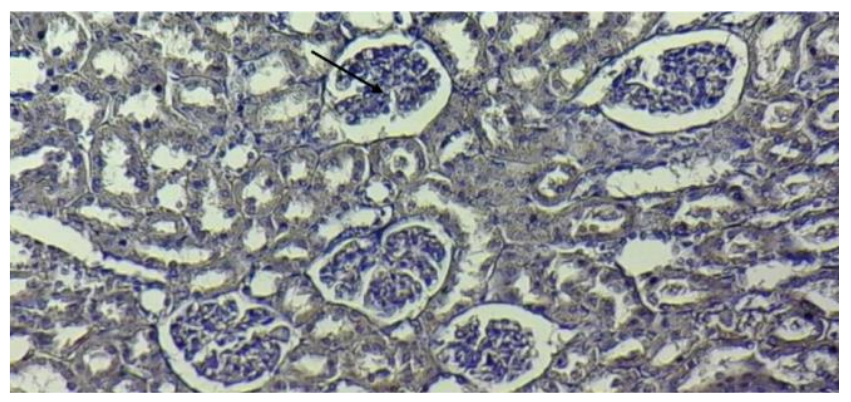

Fig. 1: Photomicrograph from rabbit kidney of a control rabbit showing normal renal tubules (blue arrows) and glomerulus (black arrows), (X 200).

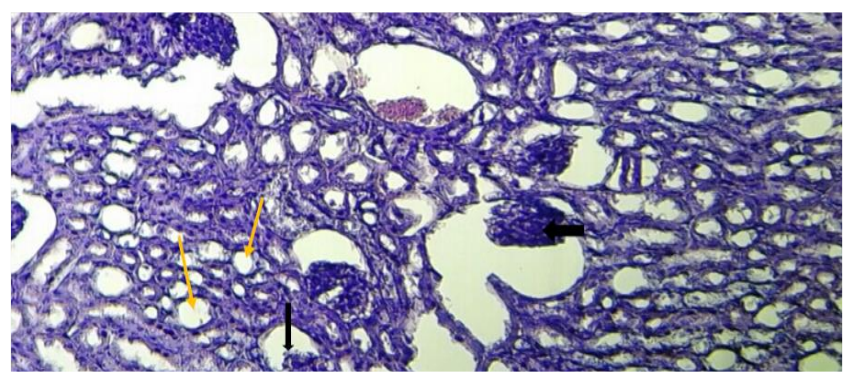

Fig. 2: Photomicrograph from rabbit kidney, of group 2, treated with diazinon for 4 weeks showing atrophy of a glomerulus (black arrows) with degeneration in the lining epithelial cells of renal tubules (yellow arrows), (X 200).

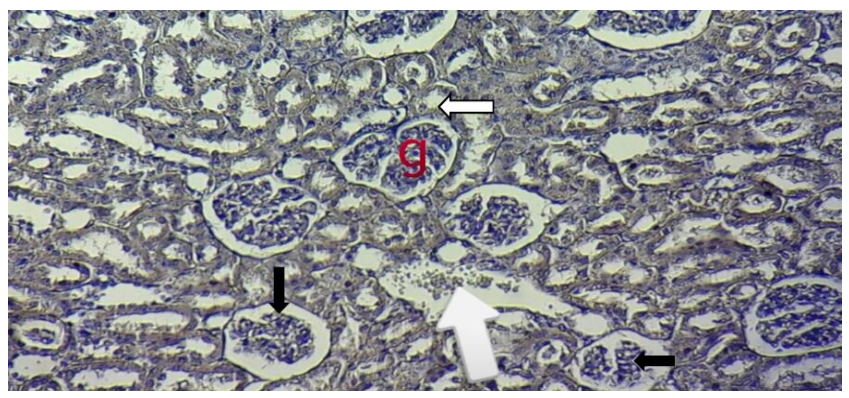

Fig. 3: Photomicrograph from rabbit kidney, of group 3, treated with diazinon for 8 weeks showing atrophy of a glomerulus (black arrows) with degeneration in the lining epithelial cells of renal tubules (d), and congestion between renal tubules (white arrow) (X 200).

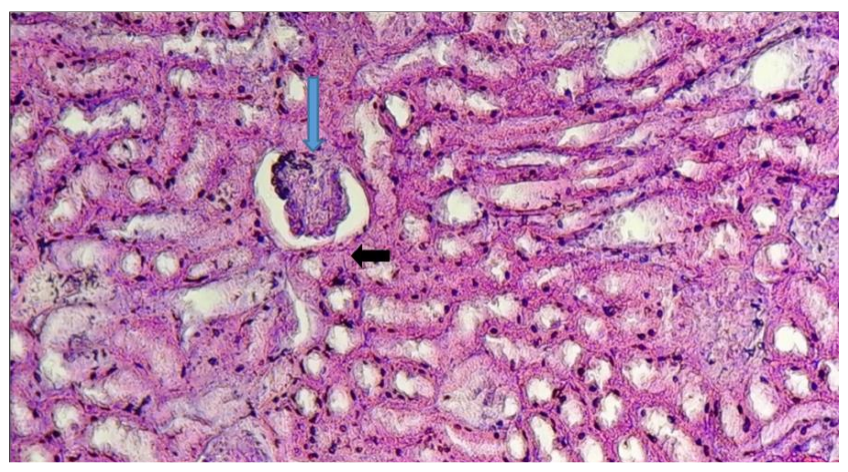

Fig. 4: Photomicrograph from rabbit's kidney of group 1 showing strong positive reaction to PAS stain, demonstrates the prominent $\mathrm{BB}$, glomerulus's (blue arrow) given red reactions in the basal lamina of the capillary loops.

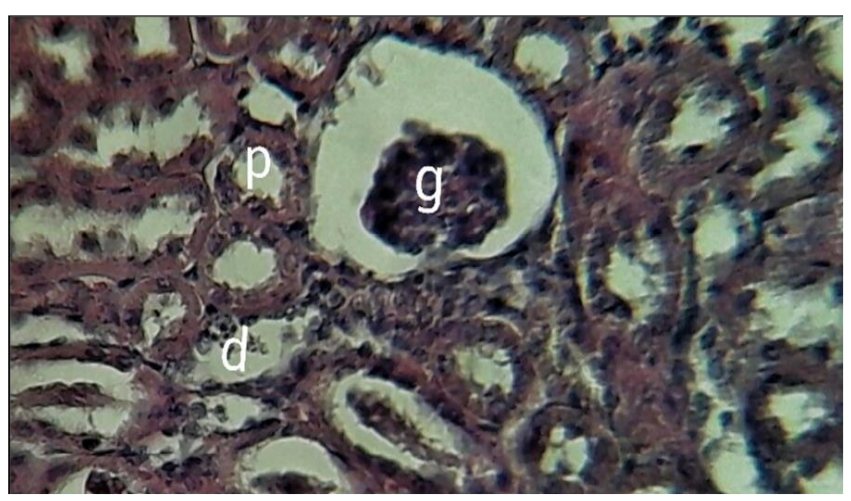

Fig. 5: Photomicrograph from rabbit's kidney of group 1 showing strong positive reaction to Best's carmine stain, demonstrates the prominent $\mathrm{BB}$, glomerulus given maganed reactions in the basal lamina of the capillary loops.

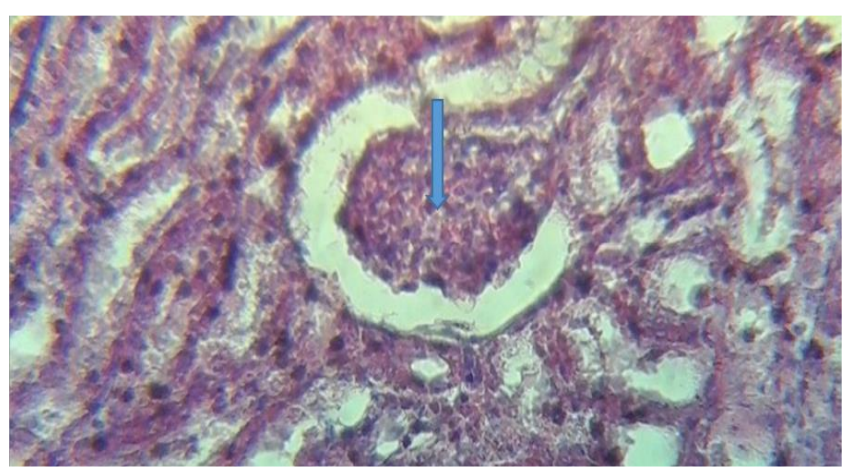

Fig. 6: Photomicrograph from rabbit's kidney of group 2 showing positive reaction to PAS stain, demonstrates the prominent BB, glomerulus's (blue arrow) given red reactions in the basal lamina of the capillary loops. 


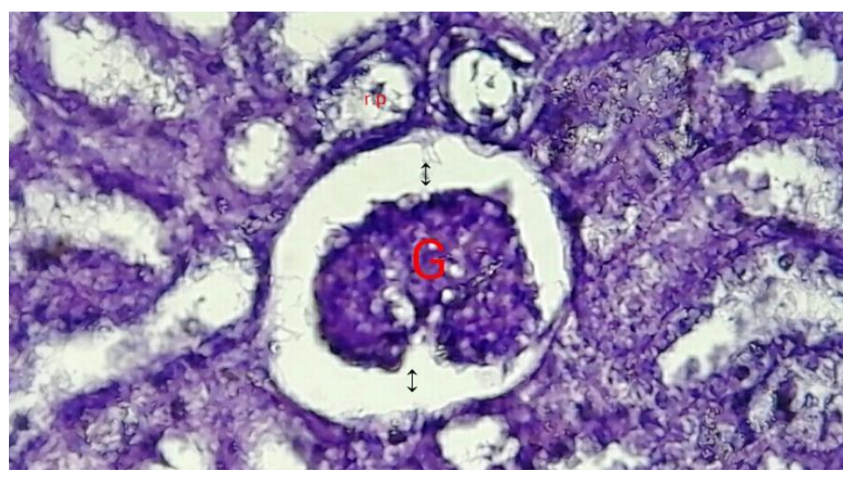

Fig. 7: Photomicrograph from rabbit's kidney of group 2 showing positive reaction to Best's carmine stain, demonstrates the prominent $\mathrm{BB}$, glomerulus given maganed reactions in the basal lamina of the capillary loops, widened of urinary space.

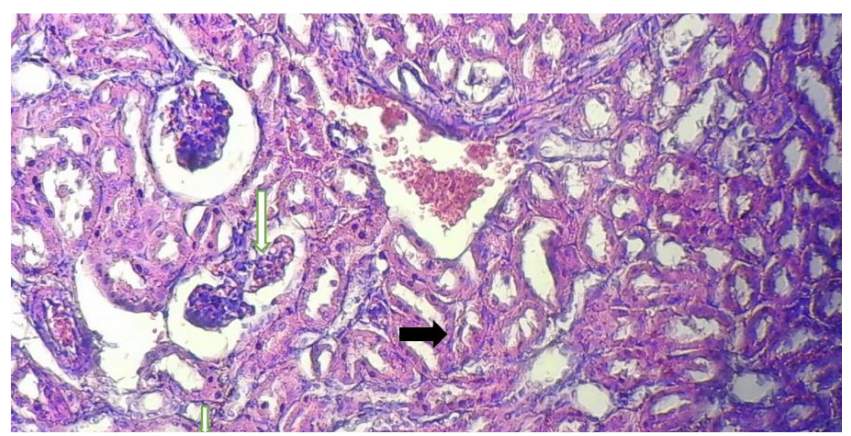

Fig. 8: Photomicrograph from rabbit's kidney of group3 showing strong positive reaction to PAS stain, demonstrates the prominent $\mathrm{BB}$, glomerulus's given red reactions in the basal lamina of the capillary loops, atrophy of glomeruli (white arrows), blood and congestion (black arrow).

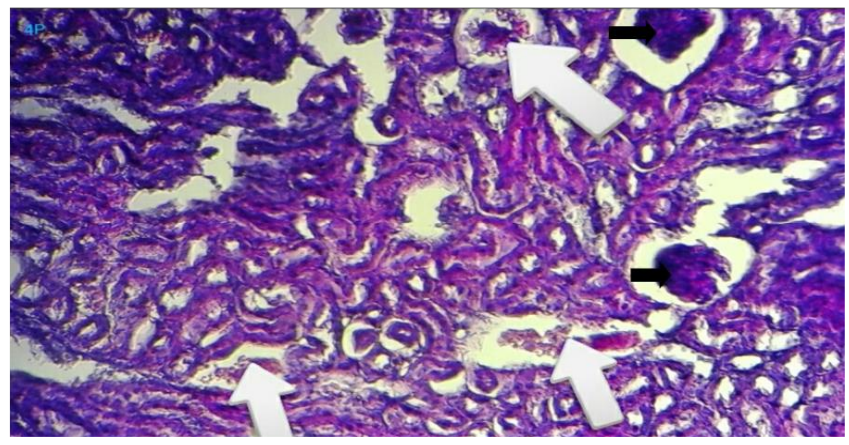

Fig. 9: Photomicrograph from rabbit kidney of group 3 showing strong positive reaction to Best's carmine stain, demonstrates the prominent $\mathrm{BB}$, glomerulus given maganed reactions in the basal lamina of the capillary loops, blood and congestion (Wight arrow), atrophy of glomeruli (black arrows).

\section{Discussion}

\section{Body weight}

In the present study, body weight marked decrease, reduced food consumption and diarrhea was the most important signs of toxicity in the exposed animals.

In group 2, and 3 marked body weight reduced were noticed this is may be due to increases in the exposed doses and increased accumulation of DZN in the blood of the exposure animals.

The present results are generally similar to those reported by Tawab et al. (8), Arab (9) and Maryam et al. (10).

\section{Histological findings}

The kidney was the first tissue for toxicant accumulation in the animals exposed to diazinon. The high concentration of diazinon in the renal tissue samples was predictable because of the increased renal blood flow, and it filters large amounts of toxins which can concentration in the kidney tubules (14).

\section{Group 1 (control group)}

Kidney tissue of the control group revealed normal histological structures, similar to those observed by other authors (15-17).

\section{Group 2 and group 3}

kidney section revealed histological changes which include that of the glomeruli were atrophied with destruction in the lining epithelial cells of renal tubules,cytoplasmic vacuolation and congested blood capillaries in between the degenerated tubules, the urine spaces is widen, diffuse prominent congested blood vessels in some glomerulus, infiltrations of lymphocyte in glomerulus and interstitial and no any changes in endothelial of renal tubules, in group 3 only showed fibrosis inter renal tubules.

This is agreement with the reported mentioned that the glomeruli were hypertrophied. After 4 weeks, the renal tubules were severely damaged and their cells showed cytoplasmic vacuolation and atrophy of some glomeruli. Blood capillaries in between the degenerated tubules were congested. These histopathological alterations in kidney were severed in animals examined in group 2 and group 3 which agreement with result of (18-22).

The histological changes in kidney we can see mild histological changes in group 2 because of Increased time of exposure (28 days), the stepwise increases in the exposure doses (14 doses) through four continuous weeks.

But in group 3 marked histological changes because of the time of exposure of diazinon are long time (for 56 days). Due to increased accumulation (every 7 days) of DZN in the blood of the exposed animals shows the readily 
absorption of diazinon through dermis and its potential to access into different tissues. The stepwise increases in the exposure doses through eight continuous weeks ( 8 dose) lead to high absorption and high concentration of the toxicant in the blood.

\section{Histochemical findings (control group)}

The kidney cortex revealed strong PAS-positive in the Basement membrane (BM) and on the brush borders (BB) of the proximal convoluted tubules (23).

In the present study, PAS and Best's carmine was moderately positive in the cells of proximal convoluted tubules and weak positive in the epithelial cells of distal convoluted tubules in control group.

\section{Group 2}

In this groups positive reaction to PAS was seen in cytoplasm of proximal convoluted cells, and on the brush borders. Weak positive reaction in the cytoplasm of proximal convoluted cells, and on the brush borders.

\section{Group3}

In this groups strong positive reaction to PAS and Best's carmine were seen in proximal convoluted cells, and on the brush borders.

The glycogen content of proximal convoluted tubular cells was more than in the distal tubular cells which is may be related to the high metabolic activity of these cells which would make them having more glycogen compared to that in the cells of the distal convoluted tubules as well as the later are less metabolically active (24).

Decreased glycogen in the proximal tubules was observed after DHC exposure. It may be related to the diazinon treatment induced destruction in the tubular brush border. This makes the tubules lose their physical and chemical protection (25) and in agreement with the decreased glycogen content in brush borders and disruption of Bowman's capsules (7).

\section{Conclusion}

Diazinon induced marked decreased in body weight in group 2 and 3. Varies degrees of harmful changes in the histological structure of kidney were observed according to the duration of action of the used diazinon, in the exposed rabbits. It is concluded that diazinon causes depletion in the total carbohydrates in the kidney tissues and this effect were linked with the concentration of the organophosphate. The histochemical finding in groups 2 (positive reaction) are mild effect as compared with group 3 (strong positive reaction).

\section{References}

1. 1-Magda KM, Afaf ALEL-Kashoury, MA Rashed, KM. j Nature and science, 7,2,1-15, ISSN 1545-0740.

2. 2-Al-Attar AM, Abu Zeid, IM. Effect of tea (Camellia sinensis) and olive (Olea europaea L.) leaves extracts on male mice exposed to diazinon. Biomed Res Int.; V2013, Article ID 461415,6 P.

3. 3-ERA. Environmental Risk Assessment for Diazinon; U.S. Environmental Protection Agency, Office of Prevention, Pesticides and Toxic Substances, Office of Pesticide Programs, U.S. Government Printing Office: Washington, DC. 2000.

4. 4-Timchalk C. Organophosphate Pharmacokinetics. Handbook of Pesticide Toxicology, Vol. 2. 2nd ed.; Krieger, R., Ed. Academic Press: San Diego, 2001: pp. 398, 936-939.

5. 5-Peterson ME, Talcot PA. Small Animal Toxicology, 2nd ed.; Elsevier: St. Louis, 2006: pp. 526-527, 941-955.

6. 6-Kalender Y, Uzunhisarcikli M, Ogutcu A, Acikgoz F, Kalender S. Effects of diazinon on pseudo cholinesterase activity and hematological indices in rats: the protective role of vitamin E, Environ Toxicol Pharmacol. 2006;22 (1):46-51.

7. 7-Yehia MA, El-Banna SG, Okab AB. Diazinon toxicity affects biophysiological and biochemical parameters in rabbits. Exp Toxicol Pathol. 2007; 59:215-225.

8. 8-Abdel-Tawab H, Mossa T M, Enayat A. Physiological and histopathological changes in the liver of male rate exposed to paracetamol and diazinon, Asian Pacific $J$ of Tropical Biomedicine, 2012, V2, ISSUI 3, P S1683-S1690.

9. 9-Arab HA, Goudarzi M, Koohi MK, Shams GR. Blood and tissue levels of diazinon in rabbit following a sub-acute dermal exposure to incremental doses. Pharmacol. 2013;7(3):213-219.

10. 10- Salehi M, Jafari M, Asgari A, Salimian M, Abbasnezhad M, Reza Haji-Hosseini, Strain-Related Different on Response of liver and kidney Antioxidant Defense System in Two Rat Strains Following Diazinon Exposure, Baqiyatallah University of Medical Scien.,J Res Med Sci .2016 Fep;18(2):e5988.

11. 11-Siti BB, Kim JH, Putri AJ, Izatus ST, Ahmad RG, Jamaludin M. Antioxidant activity of tocotrienol rich fraction prevents fenitrothioninduced renal damage in rats. Faculty of Health Sciences, Universiti Kebangsaan Malaysia, Jalan Raja Muda Abdul Aziz, 50300 Kuala Lumpur, Malaysia J Toxicol Pathol; 2013; 26: 111-118.

12. 12-Bhasin R, Mahajan R, Raina S. Acute nephrotoxicity by chlorpyrifos - an insight into its effects on mammals, Department of Anatomy, Government Medical College, Jammu, 180001, India International J of Clinical and Surgical advances 2014;2(3):12-24.

13. 13-Luna LG. Manual of Histological Staining Methods of the Armed Forces Institute of Pathology. 3rd ed., McGraw-Hill Company, New York. 1968.

14. 14-Begum Q, Begum S, Noori T. Antioxidant effect of sodium selenite on thioacetamide -induced renal toxicity. Pak J Biochem Mol Bio. 2011; 44:1-14.

15. 15-Hosaka EM, Santos OFP, Seguro AC. Effect of cyclooxygenase inhibitors on gentamycin-induced nephrotoxicity in rats. Brazil J Med Biol Res. 2004;37:979-985.

16. 16-Kumar G, Hota D, Saitia UN, Pandhi P. Evalution of analgesic efficacy,gastrotoxicity and nephrotoxicityof fixed-dose combinatios of nonselective,preferential and selsctive cyclooxygenase inhibitors with paracetamol in rats. Experimental and Toxicologic Pathology Volume 62, Issue 6, November 2010, Pages 653-662.

17. 17-Hasso RA. Histological toxic effect of nandrolone decanoate on kidney of male rabbits. Med J Basrah. 2009;27(1):19-22.

18. 18-Mona AH. Yehiaa Sabah G, El-Bannab S, Aly BO. Diazinon toxicity affects histophysiological and biochemical parameters in rabbits. Experim Toxicol Pathol. 2007;59:215-225.

19. 19- El-Shenawy NS, Al-Eisa RA, El-Salmy F, Salah O. Prophylactic effect of vitamin E against hepatotoxicity, nephrotoxicity hematological induces and histopathology induced by diazinon insecticide in mice. Curr Zool. 2009;55 (3):219-226. 
20. 20-Kammon AM, Brar RS, Banga HS, Sodhi S. Patho-biochemical studies on hepatotoxicity and nephrotoxicity on exposure to chlorpyrifos and imidacloprid in layer chickens. Vet Arhiv. 2010;80:663-672.

21. 21-Sarhan OMM, Al-Sahhaf ZY. Histological and Biochemical Effects of Diazinon on Liver and Kidney of Rabbits. Life Sci J. 2011;8(4):1183-1189.

22. 22- Heikal TM, Mossa ATH, Marci GI, Rasoul MA. Cyromazine and Chlorpyrifos induced Renal Toxicity in Rats: The Ameliorating effects of Green Tea Extract. Environm Analy Toxicol. 2012;2(5):146.
23. 23-Burkitt HG, Young B, Heath TW. Wheater's functional histology a text and color atlas, 3rd ed. Churchill Livingstone Harcourt Brace and Company limited; 1999;pp:294.

24. 24-Meter CU, Rideout BA, Gilbert M, Shivapasad HL, Oaks JI. pathology and proposed pathophsiology and diclofenac poisoning in freeliving and experimenally exposed oriental white -backed vultures (gyps bengalensis). J Wild Life Dis. 2005;41(4):707-717.

25. 25-Ogura T, Takaoka M, Yanouchi T, Oishi T, Mimra Y, Hashimoto $M$. Changes in urinary enzyme activity and histochemical findings in experimental tubular injury induced by gold sodium thiomalate. Toxicol Med. 1996;27:41-55. 